\title{
MicroRNA-I53 acts as a prognostic marker in gastric cancer and its role in cell migration and invasion
}

This article was published in the following Dove Press journal:

OncoTargets and Therapy

2 February 2015

Number of times this article has been viewed

\section{Zhengliang Zhang' \\ Jiangli Sun' \\ Zhenghai Bai' \\ Haijun $\mathrm{Li}^{2}$ \\ Shicai $\mathrm{He}^{2}$ \\ Rui Chen² \\ Xiangming $\mathrm{Che}^{2}$}

'Department of Emergency, Second Affiliated Hospital of Xi'an Jiaotong University, ${ }^{2}$ Department of General Surgery, First Affiliated Hospital of Xi'an Jiaotong University, Xi'an, People's Republic of China
Correspondence: Xiangming Che Department of General Surgery, First Affiliated Hospital of Xi'an Jiaotong University, No 277 Yanta West Road, Xi'an 7I006I, People's Republic of China Tel +862985323874

Fax +862985323874

Email cxm_xjtu@I63.com
Abstract: MicroRNA (miRNA)-153 (miR-153) has been considered as a novel tumor-related miRNA and is found to be significantly deregulated in human cancers. In this study, we found that the expression levels of miR-153 were obviously lower in gastric cancer tissues than those in matched adjacent nontumor tissues. Otherwise, miR-153 was expressed at significantly lower levels in aggressive tumor tissues. Clinical association analysis indicated that low expression of miR-153 was prominently correlated with poor prognostic features in gastric cancer. Furthermore, we demonstrated that the low expression of miR-153 was correlated with short 5 -year survival of gastric cancer patients. Multivariate Cox regression analysis indicated that miR-153 was an independent prognostic marker in gastric cancer. Our in vitro studies showed that upregulation of miR-153 reduced cell migration and invasion in MKN-45 cells. Meanwhile, downregulation of miR-153 promoted SGC-7901 cell migration and invasion. An inverse correlation between miR-153 and SNAI1 expression was observed in gastric cancer tissues. In addition, upregulation of miR-153 reduced SNAI1 expression and subsequently suppressed epithelial-mesenchymal transition (EMT) with elevated expression of E-cadherin and reduced expression of vimentin in MKN-45 cells. Furthermore, downregulation of miR-153 increased SNAI1 expression and promoted EMT in SGC-7901 cells. In conclusion, miR-153 is an independent prognostic marker for predicting survival of gastric cancer patients and may promote gastric cancer cell migration and invasion, by inhibiting SNAI1-induced EMT.

Keywords: miR-153, prognosis, SNAI1, EMT, tumor metastasis

\section{Introduction}

MicroRNAs (miRNAs) are a large class of evolutionarily conserved noncoding RNAs of 18-25 nucleotides in length that negatively regulate genes involved in many fundamental cell processes, including development, differentiation, proliferation, survival, and death. ${ }^{1}$ Recent studies have shown that miRNAs play key roles in the initiation and progression of cancer. ${ }^{2}$ Deregulation of miRNAs has been reported in various types of human cancers, including lymphoma, colorectal and breast cancer, glioblastoma, lung cancer, papillary thyroid carcinoma, and hepatocellular carcinoma, suggesting it is a hallmark of cancer. ${ }^{3-7}$ Specific miRNAs have been shown to regulate known oncogenes or tumor suppressor genes, or function as so-called "oncomiRs", or tumorsuppressor miRNAs, by directly targeting other genes involved in cell differentiation, proliferation, invasion, apoptosis, and angiogenesis in various types of cancer. ${ }^{8}$

MiR-153 is proposed as a novel tumor-related miRNA and has been found to be significantly deregulated in tumors. ${ }^{9}$ MiR-153 was downregulated in human glioblastoma, ${ }^{10}$ oral cancer, ${ }^{11}$ breast cancer, ${ }^{12}$ and ovarian cancer. ${ }^{13}$ MiR-153 induces glioblastoma cell apoptosis 
by directly targeting antiapoptosis family member B-cell lymphoma 2 (Bcl-2) and myeloid cell leukemia sequence 1 (Mcl-1). ${ }^{10}$ Inverse correlations have been observed between miR-153 and SNAI1 and ZEB2 levels in oral cancer patient samples. ${ }^{11}$ Furthermore, low expression level of miR-153 was found to be significantly related to metastasis and poor prognosis in oral cancer patients. ${ }^{11}$ Downregulation of miR153 is correlated significantly with advanced clinical stage in ovarian cancer. ${ }^{13}$ However, miR-153 was found to be upregulated in colorectal cancer ${ }^{14}$ and prostate cancer. ${ }^{15}$ Mechanistic investigations indicate that miR-153 promotes invasiveness indirectly by inducing matrix metalloprotease enzyme 9 (MMP9) production, whereas drug resistance is mediated directly by inhibiting the Forkhead transcription factor Forkhead box O3a (FOXO3a). ${ }^{14}$ MiR-153 plays an important role in promoting proliferation of human prostate cancer cells and presents a novel mechanism of miRNA-mediated direct suppression of PTEN expression in prostate cancer. ${ }^{15}$ Therefore, the functional significance of miR-153 in cancer development and progression seem to be cancer type-specific. However, the clinical significance of miR-153 in gastric cancer and its related molecular pathways involved in the development and progression of gastric cancer have not been elucidated.

In other research, epithelial-mesenchymal transition (EMT) was found to be a key process for gastric cancer cell migration and invasion, which resulted in a poor prognosis. ${ }^{16}$ MiR-153 is a novel regulator of EMT via targeting of SNAII and $Z E B 2$, which indicates its potential therapeutic value for reducing cancer metastasis. ${ }^{11}$ All these data promoted us to choose miR-153 for investigation in gastric cancer.

In this study, we demonstrate that reduced expression of miR-153 is observed in the aggressive phenotype of gastric cancer. The low expression of miR-153 is correlated with poor prognostic parameters in gastric cancer. Furthermore, miR-153 is an independent prognostic marker for predicting survival of gastric cancer patients. MiR-153 inhibits gastric cancer cell migration and invasion in vitro. Furthermore, miR-153 is inversely correlated with SNAI1 levels in gastric cancer tissues. MiR-153 suppresses SNAI1-induced EMT in gastric cells. Our results demonstrate that miR-153 potentiates the invasive behavior of gastric cancer cells by inhibiting SNAI1-mediated EMT.

\section{Materials and methods \\ Clinical samples and cell lines}

Gastric cancer tissue samples were collected from 80 patients, including 53 males and 27 females, who underwent resection of their primary gastric cancer in the Department of General Surgery at the First Affiliated Hospital of Xi'an Jiaotong
University during January 2006 to December 2008, with a median follow-up time of 29.5 months. All samples were used after obtaining informed consent. Patients did not receive preoperative chemotherapy or radiotherapy (clinicopathological data are shown in Table 1). The Xi' an Jiaotong University Ethics Committee approved all protocols, according to the Declaration of Helsinki (as revised in Tokyo 2004).

The human gastric cancer cell lines MKN-45 and SGC-7901 (Institute of Biochemistry and Cell Biology, Chinese Academy of Sciences, Shanghai, People's Republic of China) were cultured in complete Dulbecco's modified Eagle medium (DMEM) (Gibco ${ }^{\circledR}$; Life Technologies Corp, Carlsbad, CA, USA) containing 10\% fetal bovine serum (FBS) (Gibco; Life Technologies Corp) with 100 units/mL penicillin and $100 \mu \mathrm{g} / \mathrm{mL}$ streptomycin (Sigma-Aldrich Corp, St Louis, MO, USA), in a humidified incubator containing $5 \% \mathrm{CO}_{2}$, at $37^{\circ} \mathrm{C}$.

\section{Real-time quantitative reverse- transcription polymerase chain reaction ( $q R T-P C R)$}

Total RNA was isolated from gastric cancer cells using TRIZOL $^{\circledR}$ reagent (Invitrogen ${ }^{\circledR}$; Life Technologies Corp) according to the manufacturer's instructions. Total RNA was reverse-transcribed using a RevertAid ${ }^{\mathrm{TM}}$ First Strand cDNA Synthesis Kit (Thermo Fisher Scientific Inc, Waltham, MA, USA) according to the manufacturer's instructions. The PCR amplification for the quantification of the miR-153 and U6 RNA was performed using a TaqMan ${ }^{\circledR}$ MicroRNA Reverse Transcription Kit (Applied Biosystems ${ }^{\circledR}$; Life Technologies Corp) and TaqMan Human MicroRNA Assay Kit (Applied Biosystems; Life Technologies Corp). The relative expression of miR-153 was shown as fold difference relative to U6 RNA.

\section{Immunohistochemical staining}

Immunohistochemistry (IHC) was performed on paraformaldehyde-fixed paraffin sections. SNAI1 (ab117866; Abcam, Cambridge, MA, USA) antibody was used in the IHC with streptavidin peroxidase (SP-IHC) conjugated method. IHC was performed as previously reported. ${ }^{17}$

\section{Cell transfection}

The MiRNA vectors, including miR-153 expression vector (HmiR0039-MR04), the control vector for miR-153 (CmiR0001MR04), miR-153 inhibitor (HmiR-AN0214-AM04), and the negative control for the miR-153 inhibitor (CmiR-AN0001AM04), were purchased from Genecopoeia (Guangzhou, People's Republic of China). Cells were transfected with the aforementioned vectors using Lipofectamine ${ }^{\circledR} 2000$ 
Table I Clinical correlation of miR-I53 expression in gastric cancer

\begin{tabular}{|c|c|c|c|c|}
\hline \multirow{2}{*}{$\begin{array}{l}\text { Clinicopathologic } \\
\text { features }\end{array}$} & \multirow{2}{*}{$\begin{array}{l}\text { Total number of } \\
\text { patients, } n=80\end{array}$} & \multicolumn{2}{|c|}{ Number of patients } & \multirow[t]{2}{*}{$P$} \\
\hline & & Low miR-I53 & High miR-I 53 & \\
\hline \multicolumn{5}{|l|}{ Age (year) } \\
\hline$<65$ & 43 & 23 & 20 & \multirow[t]{2}{*}{0.501} \\
\hline$\geq 65$ & 37 & 17 & 20 & \\
\hline \multicolumn{5}{|l|}{ Sex } \\
\hline Male & 53 & 28 & 25 & \multirow[t]{2}{*}{0.478} \\
\hline Female & 27 & 12 & 15 & \\
\hline \multicolumn{5}{|l|}{ Histology } \\
\hline Well, moderate & 40 & 16 & 24 & \multirow[t]{2}{*}{0.074} \\
\hline Poor, signet & 40 & 24 & 16 & \\
\hline \multicolumn{5}{|l|}{ Size $(\mathrm{cm})$} \\
\hline$<5$ & 35 & 15 & 20 & \multirow[t]{2}{*}{0.260} \\
\hline$\geq 5$ & 45 & 25 & 20 & \\
\hline \multicolumn{5}{|l|}{ Depth } \\
\hline $\mathrm{T}_{1}$ & 17 & 4 & 13 & \multirow[t]{2}{*}{$0.014 *$} \\
\hline $\mathrm{T}_{2}-\mathrm{T}_{4}$ & 63 & 36 & 27 & \\
\hline \multicolumn{5}{|c|}{ Lymph node metastasis } \\
\hline Absent & 28 & 8 & 20 & \multirow[t]{2}{*}{$0.005^{*}$} \\
\hline Present & 52 & 32 & 20 & \\
\hline \multicolumn{5}{|l|}{ Lymphatic invasion } \\
\hline Absent & 23 & 8 & 15 & \multirow[t]{2}{*}{0.084} \\
\hline Present & 57 & 32 & 25 & \\
\hline \multicolumn{5}{|l|}{ Venous infiltration } \\
\hline Absent & 57 & 23 & 34 & \multirow[t]{2}{*}{$0.007^{*}$} \\
\hline Present & 23 & 17 & 6 & \\
\hline \multicolumn{5}{|l|}{ Stage } \\
\hline I, II & 41 & 13 & 28 & \multirow[t]{2}{*}{$0.001 *$} \\
\hline III, IV & 39 & 27 & 12 & \\
\hline
\end{tabular}

Note: *Statistically significant.

Abbreviation: miR-153, microRNA-153.

according to the manufacturer's instructions (Invitrogen, Life Technologies Corp).

\section{Boyden chamber and Transwell ${ }^{\circledR}$ assays}

Gastric cancer cells were resuspended with reduced serum DMEM medium, and the density was adjusted to $2.5 \times 10^{5} / \mathrm{mL}$. A $200 \mu \mathrm{L}$ cell suspension was added into the upper chamber, and $750 \mu \mathrm{L}$ DMEM medium containing 10\% FBS was added into the lower chamber. A Boyden chamber assay (NeuroProbe, Gaithersburg, MD, USA) was used to analyze gastric cancer cell migration, as previously described. ${ }^{18}$ Transwell assays were done in six-well plates with Transwell inserts equipped with $8 \mu \mathrm{m}$ pores (Nalgene ${ }^{\mathrm{TM}}$; Thermo Fisher Scientific) coated with Matrigel at 1:6 dilution (BD Biosciences, Franklin Lakes, NJ, USA), as previously described. ${ }^{19}$

\section{Western blot}

Total protein was isolated from cells in RIPA lysis buffer on ice. Protein concentration was quantified using a Bradford Protein Assay kit (Bio-Rad Laboratories, Hercules, CA, USA). Proteins were boiled before being separated by electrophoresis on sodium dodecyl sulfate polyacrylamide gel electrophoresis (SDS-PAGE) gels and transferred onto nitrocellulose membranes (Pall Corp, Port Washington, NY, USA). The following primary antibodies were used in the immunoblotting assays: SNAI1 (ab117866; Abcam), E-cadherin (24E10, number 3195; Cell Signaling, Beverly, MA, USA), vimentin (C-20, sc-7557; Santa Cruz Biotechnology Inc, Dallas, USA, USA), and GAPDH (G8140; US Biological, Swampscott, MA, USA). Horseradish peroxidase-conjugated secondary antibodies (Bio-Rad Laboratories) were used at a 1:1000-1:5000 dilution and detected using Western Blotting Luminol Reagent (sc-2048; Santa Cruz Biotechnology Inc), as described in our previous study. ${ }^{20}$

\section{Statistical analysis}

Results are expressed as mean \pm standard error of the mean (SEM). Significance was established with the SPSS statistical package for Windows Version 13 (SPSS, Chicago, IL, USA) and GraphPad Prism 5 software (GraphPad Software, Inc, San Diego, CA, USA), using a Pearson chi-squared test, a Kaplan-Meier plot, a log-rank test, a Pearson correlation 

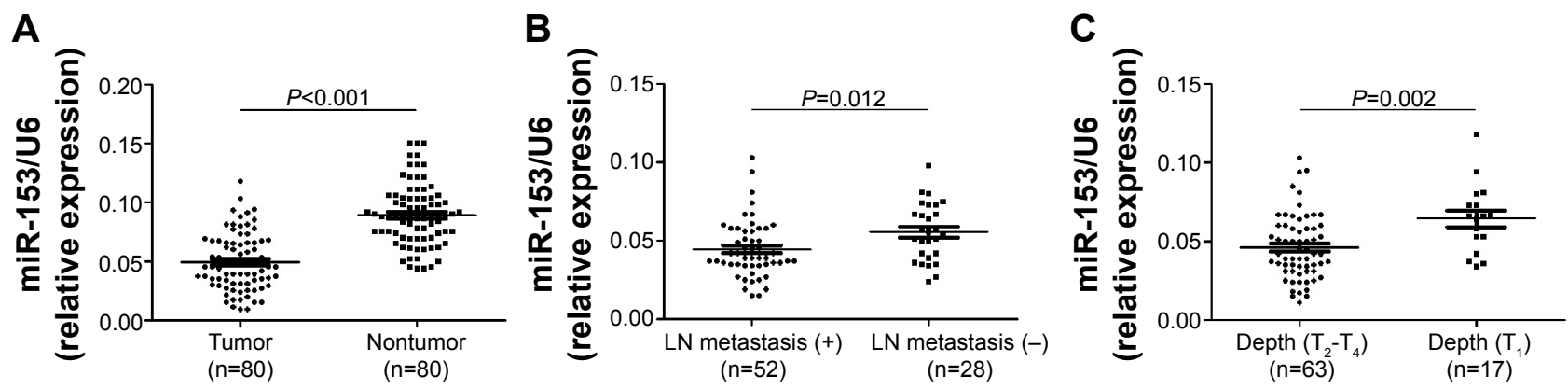

Figure I The expression levels of miR-I53 in gastric cancer specimens, comparing differences in the expression levels of miR-I53 between (A) gastric cancer tissues and matched nontumor tissues; (B) lymph node metastasis-positive and -negative tumor tissues; and (C) tumor tissues with different infiltration depths.

Notes: $T_{1}$ : mucosa $(\mathrm{m})$, submucosal $(\mathrm{sm}) ; \mathrm{T}_{2}-\mathrm{T}_{4}$ : muscularis propria (mp), subserosa (ss), serosa exposed (se), serosa infiltrating (si)

Abbreviations: LN, lymph node; miR-I53, microRNA-I53.

coefficient, or a two-tailed Student's $t$-test when appropriate. Difference were considered significant when $P<0.05$.

\section{Results}

\section{Low expression of miR-153 correlates with aggressive gastric cancer}

We tested the expression of miR-153, by qRT-PCR, and normalized against an endogenous control (U6 RNA), in 80 pairs of tumor tissues $(\mathrm{n}=80)$ and matched adjacent nontumor tissues $(n=80)$ from gastric cancer patients who received gastrectomy. The expression level of miR-153 in gastric cancer tissues was significantly lower than that in the matched adjacent nontumor tissues $(P<0.001)$ (Figure 1A). As compared with gastric cancer tissues without lymph node metastasis, miR-153 levels were prominently downregulated in the tumor tissues with lymph node metastasis $(P=0.012)$ (Figure 1B). Furthermore, miR-153 levels were obviously reduced in tumor tissues with $\mathrm{T}_{1}$ (mucosa [m], submucosal $[\mathrm{sm}])$. infiltration as compared with those in tumor tissues with $\mathrm{T}_{2}-\mathrm{T}_{4}$ (muscularis propria [mp], subserosa [ss], serosa

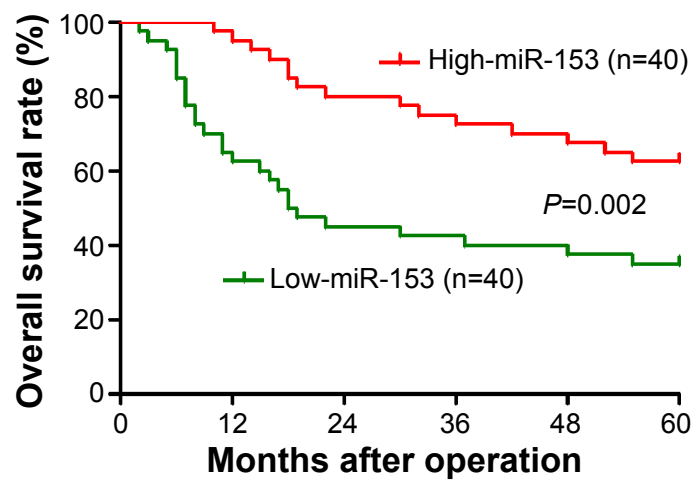

exposed [se], serosa infiltrating [si]) $(P=0.002)$ (Figure 1C). Thus, downregulation of miR-153 level was correlated with aggressiveness of gastric cancer.

\section{Clinical significance of miR-I53 expression in gastric cancer}

The expression of miR-153 was considered as either low $(n=40)$ or high $(n=40)$ according to the cutoff value, which was defined as the median of the cohort. As shown in Table 1, miR-153 was expressed at prominently higher levels in gastric cancer patients with high infiltration depth $(P=0.014)$, lymph node metastasis $(P=0.005)$, venous infiltration $(P=0.007)$, and advanced tumor stage $(P=0.001)$. Furthermore, patients with clinical survival information were analyzed by Kaplan-Meier estimation. Tumors with low expression of miR-153 indeed associated with worse overall survival and disease-free survival in gastric cancer patients ( $P=0.002$ and $P=0.005$, respectively) (Figure 2). These data indicate that miR-153 may act as a potent biomarker for predicting prognosis in gastric cancer patients. Furthermore,

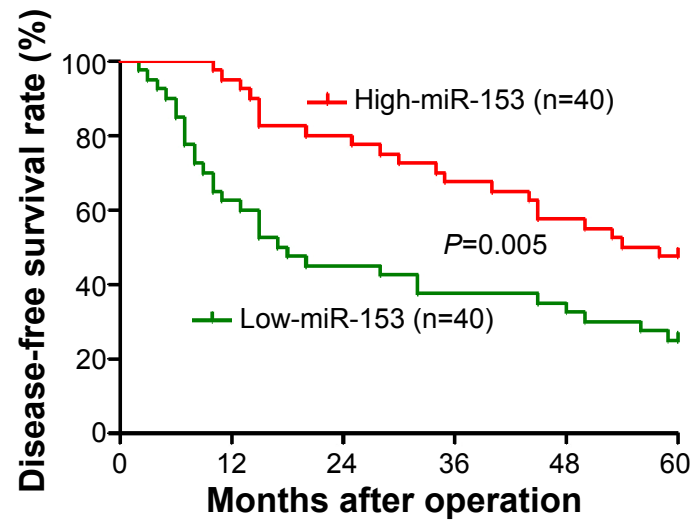

Figure 2 Prognostic significance of miR-153 in gastric cancer cases.

Notes: According to the level of miR-I53 expression, Kaplan-Meier curves of 5-year overall and disease-free survival of gastric cancer patients showed that low expression of miR-I 53 was correlated with poor prognosis. The median expression value obtained for miR-I53 of the 80 gastric cancer tissue samples detected by qRT-PCR was chosen as the cutoff value.

Abbreviations: miR-I53, microRNA-I53; qRT-PCR, quantitative reverse-transcription-PCR. 
Table 2 Multivariate Cox regression analysis of 5-year overall and disease-free survival, in 80 gastric cancer patients

\begin{tabular}{|c|c|c|c|c|c|c|}
\hline \multirow[t]{2}{*}{ Variables } & \multicolumn{3}{|c|}{ Overall survival } & \multicolumn{3}{|c|}{ Disease-free survival } \\
\hline & HR & $95 \% \mathrm{Cl}$ & $P$ & HR & $95 \% \mathrm{Cl}$ & $P$ \\
\hline Depth & 2.113 & $0.888-5.030$ & 0.091 & 1.670 & $0.787-3.545$ & 0.182 \\
\hline Lymph node metastasis & 0.749 & $0.339-1.652$ & 0.474 & 1.031 & $0.492-2.162$ & 0.936 \\
\hline Venous infiltration & 1.539 & $0.722-3.284$ & 0.264 & 1.892 & $0.940-3.808$ & 0.074 \\
\hline Stage & 3.576 & $1.251-10.211$ & $0.017^{*}$ & 3.532 & $1.266-9.858$ & $0.016 *$ \\
\hline miR-I53 expression & 0.253 & $0.08 \mathrm{I}-0.790$ & $0.018 *$ & 0.228 & $0.078-0.666$ & $0.007^{*}$ \\
\hline
\end{tabular}

Note: *Statistically significant.

Abbreviation: $\mathrm{Cl}$, confidence intervals; HR, hazard ratios; miR-I53, microRNA-I53.

miR-153 is an independent factor for predicting both 5 -year overall and disease-free survival in gastric cancer patients ( $P=0.017$ and $P=0.006$, respectively) (Table 2 ).

\section{MiR-I53 inhibits gastric cancer cell migration and invasion}

To investigate the role of miR-153 in gastric cancer, miR-153 was ectopically overexpressed in gastric cancer cell line MKN-45. As assessed by qRT-PCR, the expression of miR-153 was significantly upregulated by miR-153 expression plasmids in MKN-45 cells $(P<0.001)$ (Figure 3A). Boyden chamber assays were performed to test the effect of altering miR-153 levels, on gastric cancer cell migration. We found that upregulation of miR-153 led to a significant reduction of cell migration in MKN-45 cells $(P<0.001)$ (Figure 3B). Furthermore, as determined by Transwell assays, the number of invaded MKN-45 cells was significantly reduced after upregulation of miR-153 ( $P=0.008)$ (Figure 3B). Next, SGC-7901 cells, which showed a significant 3.2-fold elevation of miR-153 expression as compared with MKN-45 cells, were transfected with miR-153 inhibitor or negative control. MiR-153 downregulation of SGC-7901 cells was established and confirmed by qRT-PCR $(P<0.001)$ (Figure 3C). As expected, downregulation of miR-153 obviously promoted SGC-7901 cell migration and invasion $(P=0.012$ and $P=0.025$, respectively) (Figure 3D). Thus, miR-153 inhibited gastric cancer cell migration and invasion.

\section{MiR-I53 may suppress SNAII-induced EMT in gastric cancer cells}

Previous studies reported that miR-153 is a novel regulator of EMT via targeting of SNAII and ZEB2 in human epithelial cancers. ${ }^{11}$ We evaluated the correlation between SNAI1 and miR-153 expression in our gastric cancer tissue samples. The SNAI1 levels in tumors with high miR-153 expression were significantly lower than those in tumors with low miR-153 expression $(P=0.002)$ (Figure 4). Furthermore, Spearman correlation analysis indicated that miR-153 was inversely correlated with SNAI1 expression in gastric cancer $(r=-0.652)$ $(P<0.001)$. Next, MKN-45 cells that were transfected with the miR-153 control or miR-153 were subjected to western blot for SNAI1, E-cadherin, and vimentin. As assessed by immunoblotting, upregulation of miR-153 obviously reduced the expression of SNAI1 protein and inhibited EMT, with upregulation of E-cadherin and downregulation of vimentin in MKN-45 cells (Figure 5). In contrast, downregulation of miR-153 increased the expression of SNAI1 and resulted in reduced expression of E-cadherin and elevated expression of vimentin in SGC-7901 cells (Figure 5). Taken together, these data indicate that miR-153 suppresses SNAII expression that subsequently inhibits EMT progression in gastric cancer cells.

\section{Discussion}

Increasing studies have reported that miRNAs regulated carcinogenesis-related gene expression, indicating a new insight in the initiation and progression of gastric cancer. ${ }^{21}$ Recently, miR-153 was identified as a robust biomarker of oral cancer, with high positive predictive value. ${ }^{11} \mathrm{We}$ initially detected the expression level of miR-153 in 80 samples of gastric cancer tissues and paired adjacent nontumor tissues. Quantification of the data indicated that miR-153 expression in tumor tissues was significantly downregulated as compared with that in the nontumor tissues. Furthermore, miR-153 was expressed at significant lower levels in aggressive tumor than that in nonaggressive tumor. Importantly, our results showed that reduced miR-153 expression was associated with poor prognostic features in gastric cancer. Moreover, miR-153 was an independent prognostic maker for predicting overall and disease-free survival of gastric cancer patients. Altogether, our results indicate that the status of miR-153 is critical for prognosis determination in gastric cancer patients. As shown recently in colorectal cancer, expression studies of tumor samples can be confounded by stromal components 

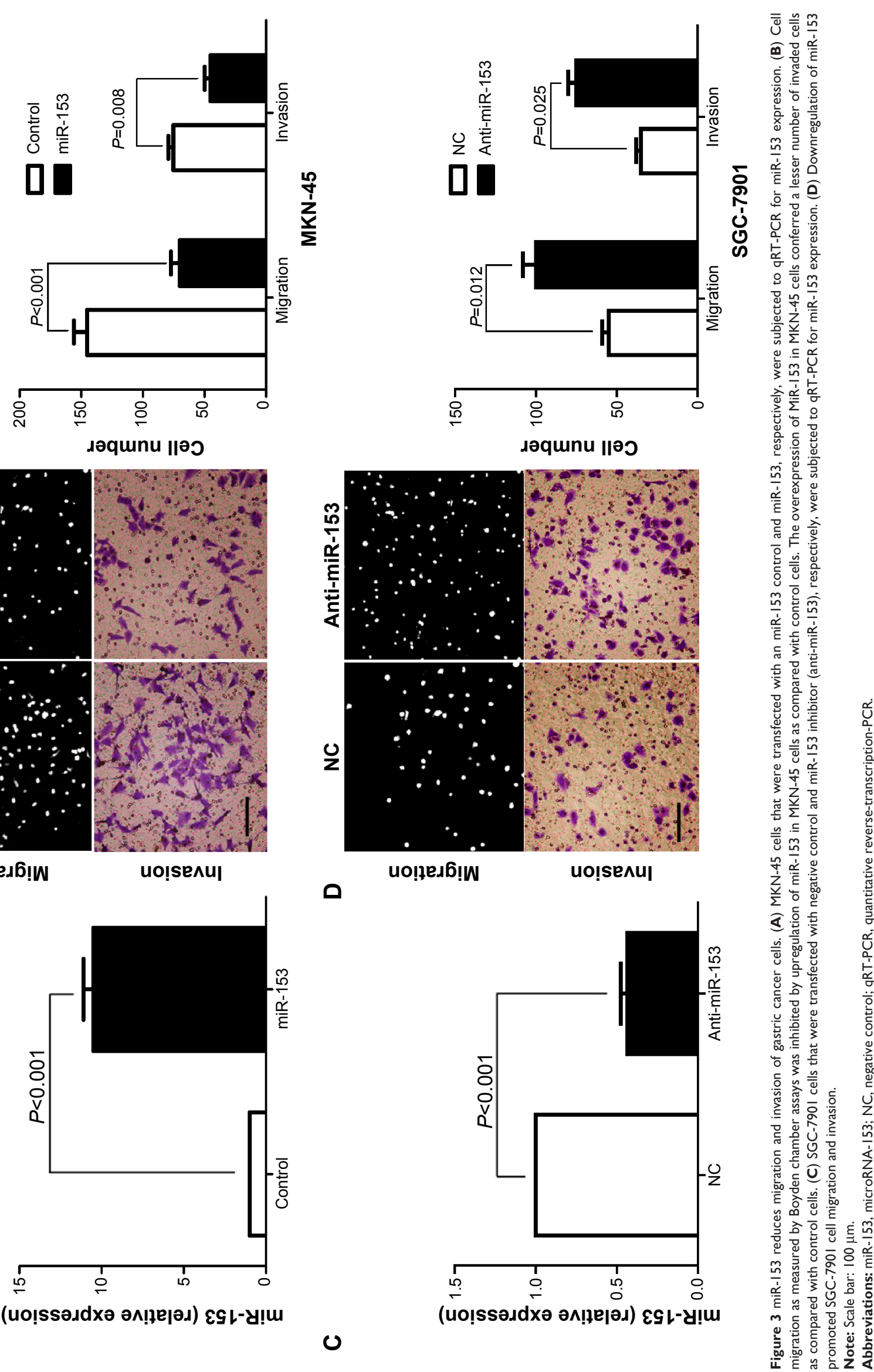

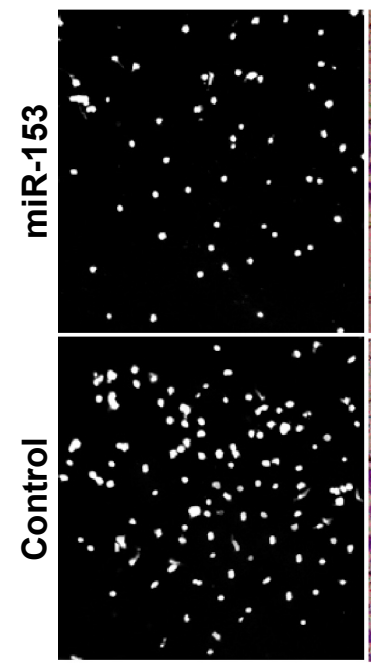

uo!ฺe. 6 !

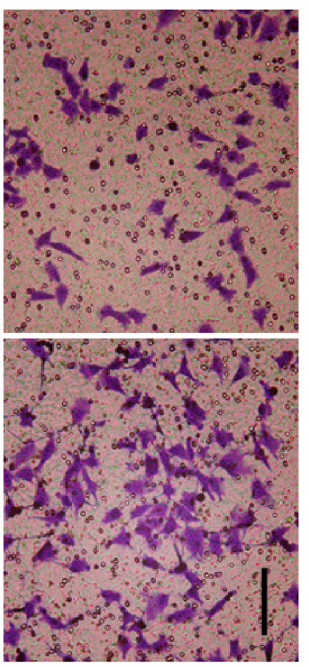

uo!̣senu|

$\boldsymbol{m}$

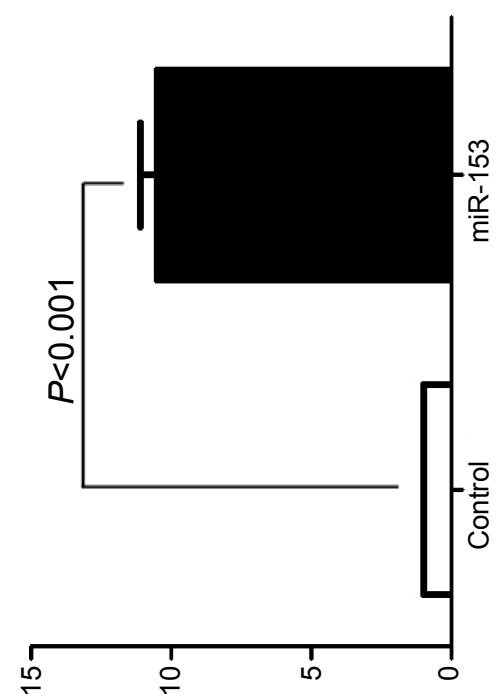

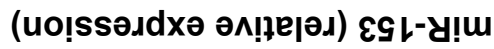

$\varangle$

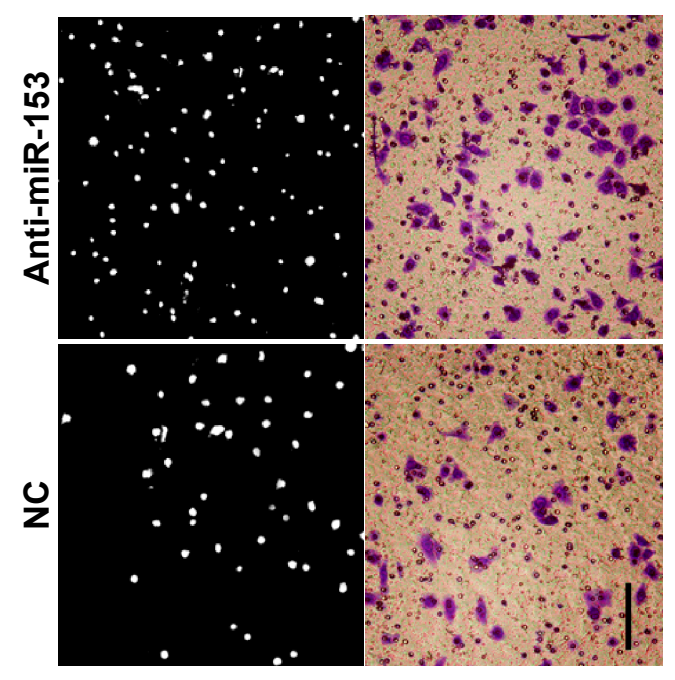

๑

$$
\text { uo!ฺes6! }
$$

uo!senu|

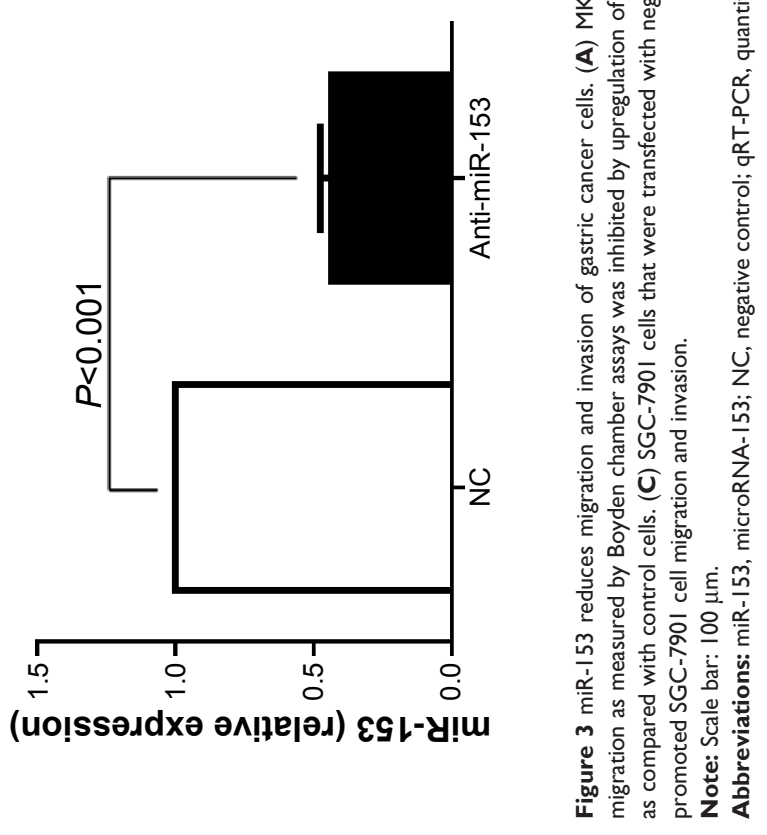




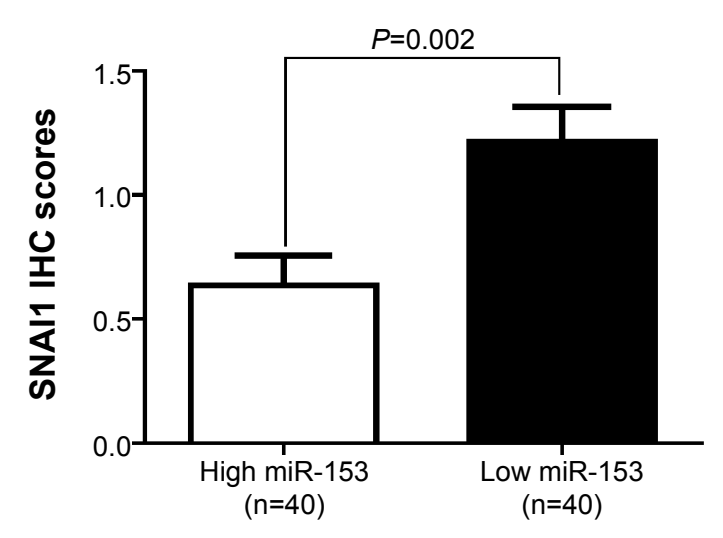

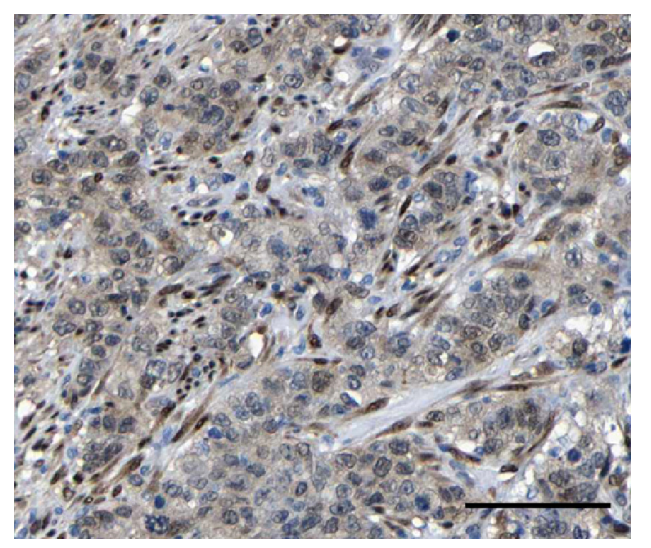

High miR-153

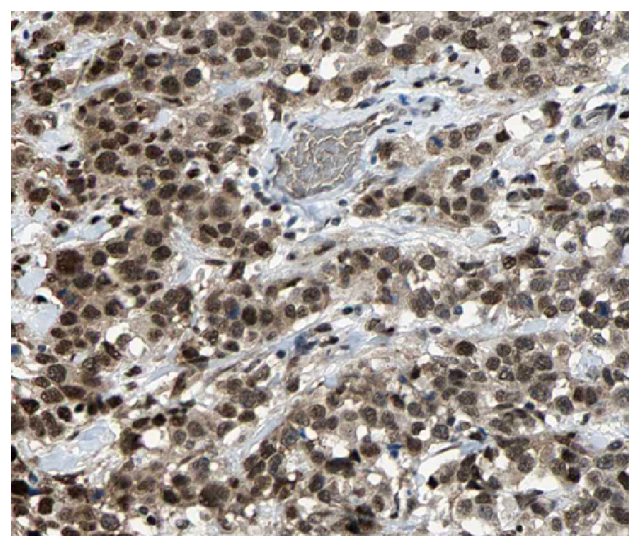

Low miR-153

Figure 4 Correlation between miR-I53 and SNAII in gastric cancer. In cases of low miR-I53 expression, there was strong SNAII protein expression in the same tissue section. In contrast, in the case of high miR-153 expression, there was weak SNAII protein expression. Quantitative data showed that the expression of SNAII in tumors with high miR-I53 expression was significantly lower than that in tumors with low miR-153 expression.

Note: Scale bar: $100 \mu \mathrm{m}$.

Abbreviations: IHC, immunohistochemistry; miR-I53, microRNA-I53.

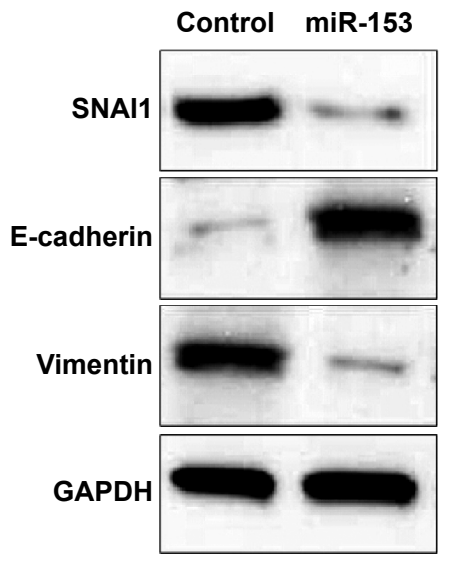

MKN-45

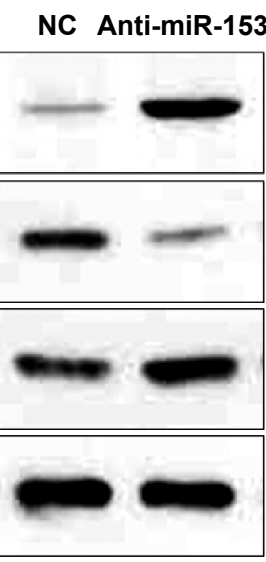

SGC-7901
Figure 5 Western blot for SNAII, E-cadherin, and vimentin.

Notes: MKN-45 cells that were transfected with an miR-153 control and miR-153, respectively, were subjected to western blot for SNAII, E-cadherin, and vimentin. Representative western blot showed that upregulation of miR-I53 obviously increased protein expression of E-cadherin and reduced SNAII and vimentin expression, in gastric cancer cells. SGC-790I cells that were transfected with miR153 inhibitor (anti-miR-153) and negative control, respectively, were subjected to western blot for SNAII, E-cadherin, and vimentin. Representative western blot showed that downregulation of miR- 153 obviously decreased protein expression of E-cadherin and increased SNAII and vimentin expression, in gastric cancer cells. Abbreviations: miR-153, microRNA-I53; NC, negative control. of the samples. ${ }^{22}$ In our studies, it was unknown whether miR-153 was expressed in stromal cells and at what level, which is a limitation of our studies.

Our gain- and loss-of-function experiments demonstrated that upregulation of miR-153 significantly reduced the number of migrated and invaded MKN-45 cells, and downregulation of miR-153 increased the number of migrated and invaded SGC-7901 cells. EMT, a dynamic and reversible cellular process, is characterized by loss of cell polarity and intracellular junctions, and the acquirement of mesenchymal features, resulting in increased gastric cancer cell migration and invasion. ${ }^{23}$ A recent study reported that miR-153 inhibited EMT by targeting SNAII and ZEB2 in human epithelial cancers. ${ }^{11}$ In our study, an inverse correlation between miR-153 and SNAI1 expression was observed in gastric cancer tissues. Furthermore, we investigated the regulatory effect of miR-153 on SNAI1, E-cadherin, and vimentin in vitro. Our data showed that upregulation of miR-153 decreased the levels of SNAI1 and suppressed EMT in MKN-45 cells. Alternately, downregulation of miR-153 
increased SNAI1 expression and promoted EMT in SGC7901 cells. Thus, miR-153 may suppress EMT by inhibiting SNAII expression in gastric cancer.

In conclusion, we found that miR-153 was downregulated in gastric cancer tissues, especially in aggressive tumor tissues. As well, the low expression of miR-153 was correlated with poor prognostic features and short survival in gastric cancer. We demonstrated that miR-153 reduced cell migration and invasion by suppressing SNAI1-induced EMT in gastric cancer cells. Taken together, we consider that miR153 may potentially act as an oncomiR and may also be a therapeutic target, in gastric cancer.

\section{Acknowledgment}

This study was supported by a grant from the National Natural Science Foundation of China (grant number 81472245).

\section{Disclosure}

The authors report no conflicts of interest in this work.

\section{References}

1. Ambros V. The functions of animal microRNAs. Nature. 2004;431(7006): 350-355.

2. Tang G, Yan J, Gu Y, et al. Construction of short tandem target mimic (STTM) to block the functions of plant and animal microRNAs. Methods. 2012;58(2):118-125.

3. Muhammad S, Kaur K, Huang R, et al. MicroRNAs in colorectal cancer: Role in metastasis and clinical perspectives. World J Gastroenterol. 2014;20(45):17011-17019.

4. Chan B, Manley J, Lee J, Singh SR. The emerging roles of microRNAs in cancer metabolism. Cancer Lett. 2014;356(2PA):301-308.

5. Romero-Cordoba SL, Salido-Guadarrama I, Rodriguez-Dorantes M, Hidalgo-Miranda A. miRNA biogenesis: Biological impact in the development of cancer. Cancer Biol Ther. 2014;15(11):1444-1455.

6. Wang WT, Chen YQ. Circulating miRNAs in cancer: from detection to therapy. J Hematol Oncol. 2014;7(1):86.

7. Faam B, Ghaffari MA, Ghadiri A, Azizi F. Epigenetic modifications in human thyroid cancer. Biomed Rep. 2015;3(1):3-8.

8. Tu K, Li C, Zheng X, Yang W, Yao Y, Liu Q. Prognostic significance of miR-218 in human hepatocellular carcinoma and its role in cell growth. Oncol Rep. 2014;32(4):1571-1577.
9. Wang $\mathrm{W}$, Peng B, Wang D, et al. Human tumor microRNA signatures derived from large-scale oligonucleotide microarray datasets. Int $J$ Cancer. 2011;129(7):1624-1634.

10. Xu J, Liao X, Wong C. Downregulations of B-cell lymphoma 2 and myeloid cell leukemia sequence 1 by microRNA 153 induce apoptosis in a glioblastoma cell line DBTRG-05MG. Int J Cancer. 2010; 126(4): 1029-1035.

11. Xu Q, Sun Q, Zhang J, Yu J, Chen W, Zhang Z. Downregulation of miR153 contributes to epithelial-mesenchymal transition and tumor metastasis in human epithelial cancer. Carcinogenesis. 2013;34(3):539-549.

12. Anaya-Ruiz M, Cebada J, Delgado-López G, Sánchez-Vázquez ML, Pérez-Santos JL. miR-153 silencing induces apoptosis in the MDAMB-231 breast cancer cell line. Asian Pac J Cancer Prev. 2013;14(5): 2983-2986.

13. Kim TH, Kim YK, Kwon Y, et al. Deregulation of miR-519a, 153, and 485-5p and its clinicopathological relevance in ovarian epithelial tumours. Histopathology. 2010;57(5):734-743.

14. Zhang L, Pickard K, Jenei V, et al. miR-153 supports colorectal cancer progression via pleiotropic effects that enhance invasion and chemotherapeutic resistance. Cancer Res. 2013;73(21):6435-6447.

15. Wu Z, He B, He J, Mao X. Upregulation of miR-153 promotes cell proliferation via downregulation of the PTEN tumor suppressor gene in human prostate cancer. Prostate. 2013;73(6):596-604.

16. Murai T, Yamada S, Fuchs BC, et al. Epithelial-to-mesenchymal transition predicts prognosis in clinical gastric cancer. J Surg Oncol. 2014; 109(7):684-689.

17. Guo HM, Zhang XQ, Xu CH, Zou XP. Inhibition of invasion and metastasis of gastric cancer cells through snail targeting artificial microRNA interference. Asian Pac J Cancer Prev. 2011;12(12):3433-3438.

18. Tu K, Zheng X, Dou C, et al. MicroRNA-130b promotes cell aggressiveness by inhibiting peroxisome proliferator-activated receptor gamma in human hepatocellular carcinoma. Int J Mol Sci. 2014;15(11): 20486-20499.

19. Li C, Yang W, Zhang J, et al. SREBP-1 has a prognostic role and contributes to invasion and metastasis in human hepatocellular carcinoma. Int J Mol Sci. 2014;15(5):7124-7138.

20. Li HJ, Che XM, Zhao W, et al. Diet-induced obesity promotes murine gastric cancer growth through a nampt/sirt1/c-myc positive feedback loop. Oncol Rep. 2013;30(5):2153-2160.

21. Li Z, Ying X, Chen H, et al. MicroRNA-194 inhibits the epithelialmesenchymal transition in gastric cancer cells by targeting FoxM1. Dig Dis Sci. 2014;59(9):2145-2152.

22. Chivukula RR, Shi G, Acharya A, et al. An essential mesenchymal function for miR-143/145 in intestinal epithelial regeneration. Cell. 2014;157(5):1104-1116.

23. Zhang ZY, Ge HY. Micrometastasis in gastric cancer. Cancer Lett. 2013;336(1):34-45.
OncoTargets and Therapy

\section{Publish your work in this journal}

OncoTargets and Therapy is an international, peer-reviewed, open access journal focusing on the pathological basis of all cancers, potential targets for therapy and treatment protocols employed to improve the management of cancer patients. The journal also focuses on the impact of management programs and new therapeutic agents and protocols on

Submit your manuscript here: http://www.dovepress.com/oncotargets-and-therapy-journal

\section{Dovepress}

patient perspectives such as quality of life, adherence and satisfaction. The manuscript management system is completely online and includes a very quick and fair peer-review system, which is all easy to use. Visit http://www.dovepress.com/testimonials.php to read real quotes from published authors. 